\title{
Marketing Channels Effectiveness in Iran: an Overview
}

\author{
Mehrdad yahyavi \\ Assistant Professor, Chabahar International University, Iran \\ E-mail: Yahyavi_m@yahoo.com
}

\begin{abstract}
Marketing plays very important role in corporate sectors. The result of this study shows that dealers, wholesalers and retailers of electronic home appliances and the individual group of customers are concerned, the researcher presents the research results for each group separately and then for total market.

The findings obtained from the analysis of information (Data) regarding the dealers of durable electronic home appliances are as follows:

1. Employees employed by dealers do not have adequate technical background while dealers have sound experience in the field of marketing and distribution. This is a strong point here.

2. Pricing system does not have any uniformity and rationale. Pricing system varies with the manufacturer, dealer or with the syndicate of dealer. This eventually affects the marketing of products.

3. Dealers guess the demand only through the customers and their choices/tastes/needs.

4. Manufacturers choose the dealers by appraising their financial status and this makes the market more monopolistic than competitive.
\end{abstract}

Keywords: Marketing, Marketing channels, Dealers

\section{Introduction}

After the Second World War, the size and character of markets changed enormously. There was a substantial increase in population. The disposable income of the average family registered an increase.

Now industrial concerns sprang up rapidly; a great variety of new products and services strengthened the rapidly developing consumer market (Thomas et al., 1995). At the same time, selling of products and services became unusually difficult, because of the high intensity of competition. It was a situation of abundant choices to the consumer and the consumer began to occupy a place of unique importance.

In particular, the consumer in the affluent world, educated as he was, and endowed with a good discretionary income at his disposal, found himself in to position to bargain in the market and get the best return for every penny he spent.

The businessmen realized that it was not enough if they somehow made a one-time sale of their product, to the consumer (Srivastava, 1991).

They found it necessary to ensure that the man who purchased their products once, comeback to them again and again whenever he needed the product.

They also had to ensure that the product was made available at a place convenient to the consumer. In addition they had to make available their products at a price that was advantageous to the consumer.

They also had to ensure that any complaint from the consumer about the e product was attended to promptly; if it needs replacing, it had to be replaced; if it required after sales servicing, it had to be provided, and that meant the emergence of marketing.

In the field of marketing, channels of distribution indicate routes or pathways through which goods and services flow, or more from producers to customers.

The most producers do not sell their goods, directly to the final users. Between producers and the final users stands a marketing channel. Thus, distribution channel has a key role in the development of marketing and it provides variety of goods in the markets for producers and manufacturers (Sherlerkar, 1991).

According to some authors distribution system has two subdivisions:

1. Channel of distribution 2. Physical distribution 
In the channel of distribution we encounter with middlemen or intermediaries processors as well as merchant middlemen, agents and facilitators.

In this chapter we discuss about merchant middlemen, who perform all marketing functions, such middlemen are specialized in one or a few marketing functions. These middlemen facilitate (provide) the process of exchange and create time, place and possession utilities through matching and sorting process.

As such, they are able to transfer the best of information from markets, customers, competitors, goods, situation in the market, suggestion for new brand (product) to manufacturers or producers (Sharma, 1995).

Intermediaries or middlemen play an important role in the marketing of product. Making the product available to the customer in the most convenient pack size is a function, which only the middlemen can perform.

The physical distribution looks after handling of goods and assures maximum customer's service. It aims at offering delivery of right goods at the right time and place to customers.

Definitions of marketing channel or channel of distribution:

Marketing channels can be viewed as sets of interdependent organizations involved in the process of making a product or service available for consumption or use.

"Marketing channels are sets of independent organizations involved in the process of making a product or service available for use or consumption (Rostogi, 2000)".

Now we'll have a standard definition from encyclopedic dictionary of marketing management.

A channel of distribution is the route along which goods and services travel from producer/manufacturer through marketing intermediaries such as wholesalers, distributors, and retailers to the final user.

The most people think in words, at least most of the time. Therefore, if the words are fuzzy (dark), so is the thinking. To sharpen our thinking one good step is to sharpen the word meanings in our vocabulary. To illustrate this point, a channel of distribution is sometimes referred to as a 'pipeline' to provide distribution of goods from manufacturer to consumers. It implies that the goods flow through it. And yet, the channel of distribution relates to the path taken by the title to the goods, not the goods themselves. They flow through a pattern of physical distribution, which can be significantly different from the channel of distribution and is a complex problem of distribution, but are a part of physical distribution (Ramaswamy, 1990).

This is an entirely different concept. It includes production and change in form, and covers what happens from beginning to end.

Perspective is always a most important part of decision making. It should be noted that the concept of channel of distribution may be an oversimplification of reality, an academic tool less used by businessmen than is implied.

It implies, further, a purity of choice made by the manufacturer between eagerly receptive middlemen.

\subsection{Channel functions and flows}

Under the systems approach the channel is now recognized as a (Porter, 1985) system involving flow of:

(a) Information (b) Promotion (c) Negotiation (d) Ordering (e) Financing and (f) Risk taking.

\section{(a) Information:}

Middlemen have a role in providing information about the market to the manufacturer: developments like change in customer demography, psychology, psychography, media habits and the entry of a new competitor or a new brand and changes in customer preference are some kind of information that manufacturers want.

Since these middlemen are close to the customer and present in the market place they can provide this information without spending cost.

\section{(b) Promotion:}

The development and dissemination of persuasive communications designed to attract customers to the offer. Promoting the product/s in his territory is another function that middlemen perform. Many of them design their own sales incentive programs aimed at building customer traffic at their outlets (Little, 1979).

\section{(c) Negotiation:}

The attempt to teach final agreement on price and other terms so that transfer of ownership or possession can be affected.

\section{(d) Ordering (Physical flow):}

Marketing-channel members communicate of intentions to buy to the manufacturers. 
(e) Financing (Payment Flow):

The acquisition and allocation of funds required to finance inventories at different levels of the marketing channel. ${ }^{10}$

(f) Risk taking (Title):

The assumption of risks connected with carrying out the channel work. The most middlemen take title to the goods and services and trade in their own name. This also enables middlemen being in physical possession of the goods, which enable them to meet customer demand at the very moment it arises.

\section{Emergence of Marketing Channel in Marketing}

The emergence and arrangement of the wide variety of distribution oriented institutions and agencies, typically called intermediaries, because they between production on the one hand and consumption on the other hand, can be explained in terms of four logically related steps in an economic process.

Intermediaries arise in the process of exchange because they can improve the efficiency of the process.

Channel intermediaries arise to adjust the discrepancy of assortment through the performance of the sorting processes.

Marketing agencies hang together in channel arrangement to provide for the reutilization of transactions. Channels facilitate the searching process.

The four steps are explained as follows:

\section{A- Efficiency Rationale for Intermediaries:}

In primitive cultures, most household needs are produced within the household.

At an early stage in the development of economic activities, however, exchange replaced production as a means of satisfying individual needs. Exchange is facilitated when there is a surplus in production over current household requirements, and when this surplus cannot be held for future consumption because of the perishable nature of the products or the lack of storage facilities Thus, if numerous households are able to effect small surpluses of different products, a basis for exchange is developed.

These conditions of exchange are more easily met when production becomes specialized and the assortment of goods broadened.

Obviously, one must account for differences, indirect and direct communication costs, in the effectiveness and efficiency of the institutions involved in the transaction, and in the quality of the contact between the channel members.

\section{B- Discrepancy of Assortment and Sorting:}

In addition to increasing the efficiency of transactions, intermediaries smooth the flow of goods and services by creating possession, place and time utilities.

These utilities enhance the potency of the consumer's assortment. One aspect of this smoothing process is that intermediaries engage in sorting function. This procedure is necessary in order to bridge the discrepancy between the assortment of goods and services generated by the producer and the assortment demanded by the consumer.

The sorting function performed by intermediaries includes the following activities:

i. Sorting out: This involves breaking down a heterogeneous supply into separate stocks that are relatively homogeneous.

ii. Accumulation: Concerns bringing similar stocks from a number of sources together into a large homogeneous supply.

iii. Allocation: Refers to breaking a homogeneous supply down into smaller and smaller lots.

iv. Assorting: This is the building up of an assortment of products for resale in association with each other.

\section{C- Reutilization:}

Each transaction involves ordering of, and paying for goods and services. The cost of distribution can be minimized if the transactions are reutilized; otherwise every transaction is subjected to bargaining, with an accompanying loss of efficiency.

Moreover, reutilization facilitates the development of the exchange systems. It leads to standardization of goods and services whose performance characteristics can be easily compared and assessed. Because of reutilization, a sequence of marketing agencies can perform more efficiently together in a channel.

\section{D- Searching:}

Buyers and sellers are engaged in a double-search process in the market place. 
The process of searching involves uncertainty because producers are not certain of consumers' needs, and consumers are not certain that they will be able to find what they want.

Marketing channels facilitate the process of searching, as when for example

i. Wholesale and retail institutions are organized by separate lines of trade such as drug, hardware, and grocery.

ii. Products such as over-the-counter drugs are widely available through thousands of drugstores, supermarkets, convenience store and even gasoline stations.

iii. Hundreds of thousands of parts are supplied to auto motive repair facilities from local jobbers within hours of the placement of orders.

\section{Role and Importance of Distribution Channels}

Distribution channel play a decisive role in the successful marketing of most products, especially consumer products.

There are several important roles for distribution channel as following.

1. Channels provide distributional efficiency to the manufacturers: In the first place, the channels bring together the makers and the users in an efficient and economic manner.

2. Channels offer the products in assortments that are usable by and acceptable to the users:

The distribution channels combine the products and components manufactured by different firms and offer them in the form of assortment's or 'packages' of items that are 'usable by' and 'acceptable to' to users.

3. Channels provide the vital input of salesmanship: The distribution channels also provide the vital input of salesmanship. In particular, they help in establishing new products in the market.

4. Channel help in merchandising: Merchandising is another important function performed by the distribution channel. Through merchandising, the channels help the principals to reinforce the awareness about the product among the customers.

5. Channel also helps implement the price mechanism: The channels also help implement the price mechanism in the market; they assist in arriving at the price level that is acceptable to the maker as well as the user.

6. Channel also promotes transfer of technology and act as change agents: In certain cases, the distribution channels go far beyond the conventional functions of distribution or distribution plus service.

\section{The Nature of Middlemen}

There are three types of middlemen that facilitate flow of goods and services from the manufacturer to the customer:

\subsection{Merchant middlemen:}

These are the intermediaries who take title to the goods and services and resell them in market. They are such as dealers, wholesalers, and retailers and are called merchants.

Merchant middlemen are very necessary for distribution system because of their role in the markets.

\subsection{Agents}

These are those intermediaries who do not take title to the goods and services but help in identifying potential customers and even help in negotiations.

They do not share risk with the manufacturers, as they do not take title to goods and services.

Thus, their names are such as, brokers, jobbers, manufacturers, representatives and sales agents. They also act on behalf of the producer only to the limited extent of prospecting, warehousing and redistributing the products.

\subsection{Facilitators}

These are independent business units that facilitate the flow of goods and services from the producer to the customer without taking title to them or negotiating for them on behalf of the producers.

They are such as transportation companies, independent warehouses, banks and advertising agencies.

The main objective of this study is to evaluate the various aspect of distribution management (marketing channels) in Iran. The following highlight the detailed objectives of the study:

1- The study of work force quality at the level of dealers and distributors in durable electronic home appliances.

2- The study of the present marketing operations at the level of dealers and distributors in durable electronic home appliances.

3- The identification of the competitive methods at the level of dealers and distributors, in durable electronic home appliances. 
4- The analysis of the kind of policy that has been used by dealers and distributor in durable electronic home appliances.

5- The measurement of the customers' satisfaction or dissatisfaction in dealing with dealers and distributors of durable electronic home appliances.

\section{Research Questions of the Study}

The research questions driving this Study are as follows:

1-How is the condition of work force quality at the level of dealers and distributors?

2-What is the condition of marketing mix at the level of dealers and distributors?

3-What kind of competitive methods are used by the level of dealers and distributors?

4-What kind of polices are followed at the level of dealers and distributors?

5-What is the level of the customers' satisfaction or dissatisfaction?

\section{Research Methodology}

In this kind of research the most common method is survey and descriptive method. Needless to say that, this method is being considered as the essence and basis of research in this thesis.

In this regard, the researcher has made an endeavor to enrich the present research by referring to a good number of books and journals relating to research methodology in human and behavioral science, specifically in commerce and business.

The research aims at making a systematic survey of marketing channels in order to characterize the role of dealers and distributors of durable consumer electronic (household) home appliances in Iran.

In the field of marketing, distribution is considered to be a link from producers to consumers. Moreover, distribution channel is being regarded as the set of interdependent marketing institutions participating in the marketing activities involved in the movement of the flow of goods or services from primary producer to the ultimate consumer.

Therefore, the study would follow the distribution channel system comprising two flows viz.

A. Channel of distribution.

B. Physical distribution.

The channel members such as mercantile agents, wholesalers and dealers are middlemen in distribution and such middlemen ale specialized in the most of the marketing functions.

These middlemen facilitate the process of exchange and create time, place and possession utilities through marketing and sorting process.

In connection with electronic appliances, the researcher will consider only home appliances as a focus.

The mode of distribution of these commodities in connection with channel members and the method of mediation of number of distributors is also being studied in terms of the efficiency as well as its impact on marketing of these commodities.

The research methodology used $\mathrm{m}$ this study is based on both survey and descriptive method.

The researcher has sought an answer to research questions in order to enable himself to review area of study from realistic angels and further to gain and

access optimum information.

Methodology gives a brief technical account of procedure adducted by Study. The methodology includes sampling design, designing of questionnaires, administration of the questionnaires, existing variables, and the statistical analysis of the date including the tests of significance employed for testing the research questions these are discussed as follows.

\section{Sampling Design}

The samples for this study have been selected from two broad types of areas: Distribution management (marketing channels) and Customers Tehran The sampling design for both the areas involved two- stage process:

Stage I: Selection of channels of distribution, and selection of customers.

\section{Stage 2: Selection of Respondents.}

The purposive sampling and stratified random sampling techniques have been used at stage one for the selection of distributors and customers in Tehran

In stage 2, sample respondents have been selected by using simple random and stratified random sampling techniques and cluster sampling. 


\section{Stage 1:}

\section{(a) Selection of Distributors:}

Distributors who have been chosen in the durable consuming electronic home appliances as business in Tehran market can be classified into three groups:

1 -Dealers

2-Wholesalers

3-Retailers

Though several distributors of these three-categories are engaged in management of distribution in Tehran, it was not possible to include all of them in the study because of the limitations of resources and lime.

Therefore, it was decided to restrict the study to merely fifty (50) 25 dealers, 10 wholesalers and 15 retailers, (table 3.1).

\section{(b) Selection of Customers of Tehran City:}

A hundred (100) customers from the city have been selected. These customers are using electronic appliances in their houses. These customers have been selected from two sources as follows:

\section{I -According to the pin-code}

2-And then according to house numbers in each area.

\section{Stage 2:}

\section{Selection of sample respondents:}

The respondents for this study were the dealers, whole sailors, retailers and customers. For these four groups (denoted as group A, B, C and D respectively), sampling techniques have been followed as:

Groups A (Dealer): The dealers who have been recognized and listed by syndicate of electronic home appliances (Cooperative Dialers) have been selected randomly from the list. The sample size is 25 .

Group B (wholesalers): The wholesalers, who have been identified by researcher and distributors in Tehran market, have been selected 10 as a sample size randomly.

Group C (retailers): The retailers who have been identified, by researcher which are approximately 100 retailers. So sample size of retailers has been selected 15 randomly.

Group D (customers): The customers were all families who have stayed in Tehran. Stratified random sampling technique has been applied to include families from all the categories from area house numbers. The sample size that has been selected is 100 families.

In the case of all sample groups, additional respondent have been selected, keeping in mind that some respondents may be unavailable or unwilling to give interview. Unavailable or unwilling respondent have been replaced by the respondents from additional lot, which have not been added to total sample so that sample size remained unchanged.

Sample size of the four respondent groups in Tehran and the total sample are illustrated as under:

Insert Table 1 about here

\section{The Sources and kinds of Data:}

Keeping in view of the survey method in this survey, the researcher utilized the two sources of information (data):

\section{A-Primary data B-Secondary data}

A-Primary data: The collection of the primary data, the researcher has applied three different techniques, which are as follows:

\section{1 - Observation}

\section{2- Interview}

\section{3- Questionnaire}

Personal interview method was followed for the collection of primary data. The purpose of the study was briefed to the respondents before they were requested to fill up the questionnaires so as to ensure their full co-operation, they were assured that the information supplied by them shall be kept strictly confidential and shall lose individual identity and shall be only used for the purposes of statistical analysis. Hundreds and fifty Respondents were interviewed by this method.

Interviews were also conducted for the verification of information from the questionnaires. 
B-Secondary Data: Analysis has been based on not only on the primary data but also on a careful study of pertinent secondary materials including books, journals, encyclopedia specialized commercial (business) and marketing directories, and reference to the library of Chamber of Commerce and Industry.

The researcher has made an attempt to locate the list and addresses of distributors and dealers, and the electronic appliances handed by them in the City of Tehran.

\section{The Existing Variables in the Research:}

With a view to judge the importance, significance and working of each one of the variables, researcher has dealt with two variables groups as follows:

1- Dependent variables; such as "The role of dealers and distributors in the marketing".

2- Independent variable such as "Work force quality, Condition of marketing operation, Competitive methods, Adopted policy and Sources of customer satisfaction/dissatisfaction".

\section{Designing the Questionnaires:}

Keeping in view the objectives of the study, four sets of Questionnaires were prepared:

a- Questionnaires 'A' was drawn for the 'Group-A' respondents-it aimed at bringing general and professional information and data relating to existing quality of work force, marketing operations, competitive methods and policies at the level of dealers.

\section{Pre-testing of the questionnaires:}

All the questionnaires were pre-tested with a view to determining the strengths and weaknesses of the questionnaires before a full-scale survey was made. As a result of pre-testing, some of the items were dropped and some others included as deemed relevant for the Study. It also helped in discovering and eliminating the ambiguity in some questions.

In this process the researcher made an attempt to prove the validity of questionnaires, on the basis of two methods as follows:

\section{A. An Armchair Validity:}

In this connection, the researcher embarked upon designing questionnaires by using his knowledge in respect to marketing and distribution with consultation and deliberation with concerned professors and authorities on the subject.

\section{B. Sampling Validity:}

The method of sampling validity used by the researcher, before embarking on distribution of questionnaires was tested on few chosen members. Few of typical members are selected randomly and accordingly questionnaires were distributed amongst them at two different limes.

Therefore, the validity of questionnaires was confirmed by comparing them to one another.

\section{Universe of Research:}

The universe in this research is all of the dealers and distributors (retailer \& wholesaler) of durable consuming electronic home appliances and people who are staying as household as customers in Tehran.

As a whole these groups of the marketing channel members, take the risk of sales and distribution of above-mentioned appliances.

\section{Data Analysis}

The data collected through the questionnaires was tabulated, analyzed, and interpreted. However, before starting the work of tabulation and analyzing all the questionnaires were edited very carefully for completeness.

To maintain accuracy and uniformity as far as practicable all possibilities of statistical errors and bias were minimized. In some questionnaires in which all the questions were not answered the respondents were requested to supply the missing information. The tabulation of the information supplied in the questionnaires was done both manually and through electronic devices. The tabulated data was analyzed with the help of some statistical tools.

In order to measure the qualitative responses such as opinion, attitude, perception etc, the qualitative scale was converted to quantitative one.

For example; to the response, if a respondent ranked on attribute in any place of five point Likert-type scale comprising of: Poor, fair, good, very good and excellent, that was converted to quantitative scale by taking poor as one; Fair as two; good as three; very good as four; and excellent as five.1 
This was based on the assumption that the difference between poor and fair, is the same as between fair and good and very good and excellent i. e., the difference between different categories were treated as equally spaced.

By quantifying the qualitative scale it became possible to make use of statistical analysis.

\section{Use of Statistical Tools}

Simple statistical tools like percentage mean, mode, variance; tests of significance have been used to analyze data. These are as follows:

a) Weighted mean score:

'Weighted mean score' has been used to measure the level of the attributes, opinions, which were scored by individual respondents on the five - point Likert - type scale.

b) Variance:

It is a powerful tool to test the research questions such as finding out the equality of two means or several means.

It is widely used in large- sealed samples. In this study multiple regressions has been implemented to test and to measure the significant co-relation between attributes and opinions of the respondents (customers).

The first research question may be put as follows:

"How is the condition of work force quality at the level of dealers at Tehran market?"

In order to study and generalize this research question the researcher should analyzed and tested the questions; 1, 2, 3, 4 respectively.

Insert Table 2 about here

According to the answers to question 1, given by dealers, the issue of academic background can he report as below?

$56 \%$ of them have non-technical background.

$44 \%$ of them have technical background.

The value extracted from the mono-sample test $x^{2}$, which is 0.360 in value with the d.f. I also reveal that there is no significant difference between dealers with technical background and dealers who have non-technical background. This makes no important distinction between dealers.

Insert Table 3 about here

According to the answers to question 2, given by dealers, the importance of education can be illustrated as following:

$17.4 \%$ of them introduced the accountants as the most educated staff in their staff-designation.

$47.8 \%$ of them regarded the salesmen as most advocated.

$34.8 \%$ of them believed that the manager is the most educated staff.

The value extracted from the mono-sample test $x^{2}$ which is 3.217 in value with the d.f.2 also reveals that there is no significant difference among these three above-mentioned groups at the level of $\alpha=0.05$.

Insert Table 4 about here

According to the answers to question 3, given by dealers, the role of experience can be shown as follows:

$4 \%$ of dealers have gained experience of less than one year.

$16 \%$ of them have experience of $1-5$ years.

$24 \%$ of them have $5-10$ years experience. $20 \%$ of them possess $10-15$ years, background,

$36 \%$ of them have been in such a profession in a period of more than fifteen years.

The value extracted from the mono-sample test $x^{2}$ which is 6.800 in value with the d.f 4 also reveals that there is no significant difference among the discussed groups at the level of $\alpha=0.05$.

So we cannot generalize that the majority of dealers have less or much experience in marketing and distribution.

Insert Table 5 about here

According to the answers to question 4, given by dealers (see table-5), the relation of education with dealing can be analyzed as follows:

$8 \%$ of them believed that there is a relation between them.

$4 \%$ of them maintained that there is less relation between them.

$16 \%$ of them argued that there is a relative relation. 
$40 \%$ of them declared that there is much relation between education and dealing.

$32 \%$ of them stated that there is very much relation between their education and present job.

\section{Conclusion}

As far as the analysis of the three groups of distributors namely; dealers, wholesalers and retailers of electronic home appliances and the individual group of customers are concerned, the researcher presents the research results for each group separately and then for total market.

The findings obtained from the analysis of information (Data) regarding the dealers of durable electronic home appliances are as follows:

1. Employees employed by dealers do not have adequate technical background while dealers have sound experience in the field of marketing and distribution. This is a strong point here.

2. Pricing system does not have any uniformity and rationale. Pricing system varies with the manufacturer, dealer or with the syndicate of dealer. This eventually affects the marketing of products.

3. Dealers guess the demand only through the customers and their choices/tastes/needs.

4. Manufacturers choose the dealers by appraising their financial status and this makes the market more monopolistic than competitive.

\section{References}

Porter, Michael. (1985). Competitive Advantage. Publisher, Michael, E. Porter.

Rostogi, Rajiv. (2000). Electronic and Information Technology Production Trend in 2000. The Journal of Electronics Information Planning, Vol. 28, No. 3 December.

Sharma, S. D. (1995). Encyclopedic Dictionary of Marketing. Anmol Publication, P.T.V. L.T. D, Vol-2.

Sherlerkar, S. A. (1997). Marketing Management. Himalaya Publish House.

Srivastava, K. P. (1991). Marketing Management in Developing Economy. Published by S. K. Ghai, New Delhi.

Thomas, T. Nagle., and Reek K. Holden. (1995). The Strategy and Tactic of Pricing. Prentice- Hall.

Table 1. The distribution of sample

\begin{tabular}{|c|c|c|c|c|c|}
\hline Total & $\begin{array}{c}\text { D: } \\
\text { Customers }\end{array}$ & $\begin{array}{c}\text { C: } \\
\text { Retailers }\end{array}$ & $\begin{array}{c}\text { B: } \\
\text { Wholesalers }\end{array}$ & $\begin{array}{c}\text { A: } \\
\text { Dealers }\end{array}$ & $\begin{array}{c}\text { Groups } \\
\text { Sample size }\end{array}$ \\
\hline 150 & 100 & 15 & 10 & 25 & Samples \\
\hline 150 & 100 & 15 & 10 & 25 & Total \\
\hline
\end{tabular}

Q.1- Would you please advise me about your academic background?

Table 2. Measuring the academic background

Means: 1.440

Mode: 2

Variance: 514

Std. Dev: 717

\begin{tabular}{|l|l|l|l|l|}
\hline $\begin{array}{l}\text { Cum } \\
\text { Percent }\end{array}$ & V.P & Percent & Frequency & Value \\
\hline 56 & 56 & 56 & 14 & 1 \\
\hline 100 & 44 & 44 & 11 & 2 \\
\hline & 100 & 100 & 25 & Total \\
\hline
\end{tabular}


Table 3. Frequency distribution of education

Means: 2.174

Mode: 2

Variance: 514

Std. Dev: 717

\begin{tabular}{|l|l|l|l|l|}
\hline $\begin{array}{l}\text { Cum } \\
\text { Percent }\end{array}$ & V.P & Percent & Frequency & Value \\
\hline 17.4 & 17.4 & 16 & 4 & 1 \\
\hline 65.2 & 47.8 & 44 & 11 & 2 \\
\hline 100 & 34.8 & 32 & 8 & 3 \\
\hline & $\begin{array}{l}\text { No } \\
\text { Response }\end{array}$ & 8.0 & 2 & 0 \\
\hline & 100 & 100 & 95 & Total \\
\hline
\end{tabular}

Table 4. Measuring the experience

Means: 3.680

Mode: 5

Variance: 1.560

Std. dev: 1.249

\begin{tabular}{|l|l|l|l|l|}
\hline $\begin{array}{l}\text { Cum } \\
\text { Percent }\end{array}$ & V.P & Percent & Frequency & Value \\
\hline 4.0 & 4.0 & 4.0 & 1 & 1 \\
\hline 20.0 & 16.0 & 16.0 & 4 & 2 \\
\hline 44.0 & 24.0 & 24.0 & 6 & 3 \\
\hline 64.0 & 20.0 & 20.0 & 5 & 4 \\
\hline 100 & 36.0 & 36.0 & 9 & 5 \\
\hline & 100 & 100 & 25 & Total \\
\hline
\end{tabular}

Table 5. The connection between job and education

Means: 3.840

Mode: 4

Variance: 1.390

Std. dev: 1.179

\begin{tabular}{|l|l|l|l|l|}
\hline $\begin{array}{l}\text { Cum } \\
\text { Percent }\end{array}$ & V.P & Percent & Frequency & Value \\
\hline 8.0 & 8.0 & 8.0 & 2 & 1 \\
\hline 12.0 & 4.0 & 4.0 & 1 & 2 \\
\hline 28.0 & 16.0 & 16.0 & 4 & 3 \\
\hline 68.0 & 40.0 & 40.0 & 10 & 4 \\
\hline 100 & 32.0 & 32.0 & 8 & 5 \\
\hline & 100 & 100 & 25 & Total \\
\hline
\end{tabular}

